El Guiniguada • Revista de investigaciones y experiencias en Ciencias de la Educación

\title{
LA REVISTA INTERUNIVERSITARIA DE FORMACIÓN DEL PROFESORADO (RIFOP). UNA VISIÓN PERSONAL
}

\author{
José Emilio Palomero Pescador \\ RIFOP
}

Recibido: 24/03/2015/Aceptado: 14/04/2015

\section{DESDE Mi VENTANA}

Mi primer contacto profesional con la formación del profesorado tuvo lugar en octubre de 1973, en la Escuela Universitaria de Magisterio de Zamora (Universidad de Salamanca). Me fascinaba aquel trabajo de profesor de pedagogía, que sin embargo perdí para siempre unos meses más tarde. Un año después, en octubre de 1974, fui contratado como catedrático interino de psicología en la Escuela Universitaria de Magisterio de Teruel (Universidad de Zaragoza), puesto que desempeñé durante más de una década, hasta mi nombramiento como profesor titular de Escuela Universitaria, área de Psicología Evolutiva y de la Educación. Primero en Teruel, hasta 1990, y después en la Facultad de Educación de Zaragoza, donde continúo como profesor emérito.

Quizá algunas de estas circunstancias personales - mis puestos de trabajo en Teruel y Zaragoza- influyeron de alguna forma en que fuese yo el elegido para gestionar la Revista Interuniversitaria de Formación del Profesorado (RIFOP); y también para que su sede social se viniera conmigo de Teruel a Zaragoza cuando se produjo mi traslado; y para que lo que comenzó siendo tarea provisional, terminase prolongándose hasta el presente. Así que fue a causa de un conjunto de casualidades como me convertí en Editor de la RIFOP, que en mi opinión -y en la de Google Scholar Metrics- es una de las principales revistas de educación de entre todas las que se editan en español en el mundo, aunque no tenga el sello de la FECY'T, ni esté indizada en el ISI o SCOPUS.

Cuando fundamos la RIFOP yo ya era profesor Titular de Escuela Universitaria, así que si asumí responsabilidades en ella no fue para acumular méritos, sino porque estaba convencido de estar ante un proyecto de gran valor, con el que merecía la pena comprometerse. También por el placer de contribuir a desarrollar una iniciativa pedagógica interesante, un proyecto colectivo con contenido social y profundas raíces históricas. El camino, sin embargo, no fue fácil, aunque resultó interesante recorrerlo. Y el tiempo de dedicación inmenso, pero insuficiente. Se te acumula el 
trabajo, o simplemente ves crecer la bandeja de entrada del correo electrónico y sientes impotencia. Desde aquí pido disculpas a quienes no pude atender con la rapidez y consideración merecidas... Gestionar una revista es una misión casi imposible..., jamás te pones al día, siempre hay tareas pendientes. Y cuando la revista pertenece a una ONG intelectual, como es el caso de la RIFOP, las cosas pueden ser especialmente complejas. No tienes infraestructuras ni compensaciones de ningún tipo, y todo queda en manos de la gratuidad y el voluntarismo.

\section{INICIOS Y ANTECEDENTES}

Corría el 21 de abril de 1985 y en la llanura castellana, esa a la que tanto cantó Machado, en Valladolid, en el acto de clausura del II Seminario Estatal de Escuelas Universitarias de Magisterio, los trescientos asistentes al mismo, procedentes de toda España, acordaron fundar la Revista Interuniversitaria de Formación del Profesorado (RIFOP). Continuación de la antigua Revista de Escuelas Normales. Desde aquel momento fundacional han pasado treinta años.

Por otra parte, el 6 de abril de 1987, en Teruel, en el acto inaugural del III Seminario Estatal de Escuelas Universitarias de Magisterio, se presentó ante cuatrocientos profesores «normalistas», llegados desde innumerables rincones de España, el número cero de la RIFOP, que actualmente tiene en imprenta su número 82 (Abril 2015). Con ello se ponía en marcha la continuación de la antigua Revista de Escuelas Normales, una publicación de regeneración normalista que nació en Guadalajara -en enero de 1923- a partir del Boletín de Escuelas Normales (1922), y que se publicó por última vez en mayo de 1936, excepción hecha de un número experimental que vio la luz en julio de 1970 .

\section{ENFOQUE}

Señala Aubert (2007) que fue a través de la Revista de Escuelas Normales, la Revista de Pedagogía, el Boletín Escolar, La Escuela Moderna y el Boletín de la Institución Libre de Enseñanza, como se difundieron ideas nuevas en España.

En línea con lo anterior, la RIFOP nació con la intención de rescatar el nombre y el espíritu de renovación pedagógica de la Revista de Escuelas Normales, dispuesta a seguir bregando por la mejora de la formación del profesorado y a convertirse en una tribuna de reflexión crítica desde la que contribuir a la reforma de los planes de estudio, al acortamiento de las distancias teoría/práctica, a enriquecer la valoración social y profesional del profesorado de las Escuelas Universitarias de Magisterio, a luchar por la conversión de la diplomatura de Magisterio en licenciatura, mejorando así la preparación profesional de los educadores y educadoras de las futuras generaciones. 
Actualmente, la RIFOP es una revista consolidada, cuyo enfoque continúa centrado en la modernización y enriquecimiento de la formación del profesorado y en las reformas pedagógicas de corte progresista, con el objetivo de promover un debate científico de calidad en torno a temas clave de las Ciencias de la Educación. Al mismo tiempo, la revista apuesta, como objetivo global, por el fortalecimiento de la comunidad científica internacional en el campo de las Ciencias de la Educación. En este sentido, su entidad editora -la Asociación Universitaria de Formación del Profesorado (AUFOP) - ha organizado, en colaboración con diferentes universidades, un considerable número de congresos internacionales de formación del profesorado que, fundamentados en los debates de la propia revista, son después fuente de nuevas discusiones científicas en la misma.

En los treinta años transcurridos desde aquel 21 de abril de 1985 hasta hoy, la RIFOP ha publicado un total de 83 números con participación de más de 1200 autores de todo el mundo, pertenecientes a numerosas universidades. Ellos son sus verdaderos protagonistas.

\section{ÍNDICE DE IMPACTO}

En 1985, Ana Belén y Víctor Manuel cantaban "No seré nunca juguete roto / no estaré arriba de cualquier modo / En mi trabajo no uso los codos / con lo que tengo me basto y sobro / No seré nunca juguete roto / que antes de serlo me planto y corto".

En la misma fecha y con idéntica mentalidad, iniciaba su andadura la RIFOP, que como tantas otras revistas aspiró siempre a conseguir el reconocimiento de la comunidad académica internacional. Pero nunca a codazos ni de cualquier modo, pues para ese viaje -como dice la canción- me planto y corto. En este sentido, la RIFOP ha evitado siempre la tentación del mercadeo de los índices de impacto (nunca exigió una cita, por ejemplo), indicadores a los que convendría renunciar como referentes por excelencia de la calidad de una revista, para ser sustituidos por un análisis en profundidad de los saberes que aporta cada artículo. En realidad los índices de impacto solo sirven para conocer la visibilidad de una revista, siendo poco útiles para determinar la calidad de sus artículos, o la relevancia de sus autores.

En todo caso son muchas las valoraciones positivas que ha recibido la RIFOP. Entre ellas destaco las siguientes:

- En 2006 ocupó la posición 2 sobre 136 en el índice de impacto de Revistas de Educación de IN-RECS.

- Diferentes investigaciones del GRUPO EC3, Universidad de Granada, asignan a la RIFOP las posiciones 6 (2001/2010), 6 (2002/2011), 9 (2007/2011), 
7 (2008/2012) y 11 (2009/2013), en el Índice H de las Revistas Españolas de Ciencias Sociales de Google Scholar Metrics (Educación).

- Guereña, Ruiz Berrio y Tiana Ferrer (1994), incluyen la RIFOP entre las diez principales revistas españolas de educación.

- Para Checa Godoy (2002) la RIFOP es una revista ambiciosa que viene a representar lo mismo que representó la Revista de Escuelas Normales en los años veinte y treinta del siglo XX.

- Según Fernández-Cano y Bueno (2002) la RIFOP es una de las diez mejores revistas españolas de investigación educativa.

- Para García Sánchez, Rodríguez Pérez y González Sánchez (2005) el factor de impacto de la RIFOP es el quinto más alto de las revistas españolas de educación en 2003, comparable al de muchas revistas en inglés incluidas en el ISI.

- Según Romera-Iruela (2011) la RIFOP es la revista más relevante en la producción de artículos sobre investigación-acción.

\section{A MODO DE CONCLUSIÓN}

Concluyo esta breve visión personal con un fragmento de "La flecha", ese poema de Pacheco (Cervantes 2009) que se me antoja metáfora del vuelo de la RIFOP:

No importa que la flecha no alcance el blanco

mejor asi

No capturar ninguna presa

No bacerle daño a nadie

pues lo importante

es el vuelo la trayectoria el impulso

el tramo de aire recorrido en su ascenso

la oscuridad que desaloja...

\section{Nota}

Las referencias completas de los trabajos citados en este artículo están disponibles en: Palomero Pescador, José Emilio (2015). Índice de impacto de la RIFOP [http:/ / aufop.com/aufop/paginas/ view/1/home]. Consultado el día 15 de marzo de 2015.

reifop@gmail.com 